\title{
HistóRIa E DOCUMENTÁRIOS: REFLEXóEs PARA O USO EM SALA DE AULA
}

\author{
ERIC DE SALES
}

\begin{abstract}
Resumo
Não há consenso se o uso de documentários em sala de aula é uma forma de mostrar a "verdade" para os alunos. A polêmica vem uma vez que existe consenso de que esse gênero fílmico retrata a "realidade como ela é". Este artigo, que surgiu das discussóes, como docente, com a professora doutora Diva do Couto Gontijo Muniz, da disciplina Prática de Ensino 01, na Universidade de Brasília, busca apresentar algumas reflexóes de como desenvolver o uso de documentários em sala de aula. A proposta é analisar as películas mediante um olhar crítico, compreendendo que há subjetividades nas abordagens - como a visão do diretor, a perspectiva do roteirista, a escolha das falas e das imagens. Sob este ponto de vista, fornecer aos alunos subsídios para entender a produção cinematográfica cumprindo, assim, um dos pontos tâo almejados pela atual política educacional brasileira: tornar o aluno cidadão crítico.
\end{abstract}

Palavras-chave: ensino de História, documentário, narrativa.

\section{History and documentaries: approach for a classroom using}

\section{Abstract}

There is no agreement about the using of documentaries in the classroom as a tool to show to the students the truth. The polemic comes from classifying the gender of the movies, which made movie's/film's production hierarchical, and also their using in the classroom. This has the aim to show some possibilities about how documentaries can be used in the classroom. Documentaries are analyzed from a particular point of view, such as the view of the director, the writer's perspective, the choice of the characters' speech. So, the proposal is to analyze them under a critical view. From this point of view, it attempts to give the students the tools to understand film's production. This way so, it would be possible to achieve one of the aims of Brazilian's educational politic: turn the student a critical citizen. KeY wORDS: teaching History, documentary, narrative 


\section{Revista Solta a Voz, v. 20, n. 2}

\section{FILMES, ENSINO, SALA DE AULA: O INÍCIO DE UMA HISTÓRIA}

Pensar a respeito do uso de novas mídias e tecnologias em sala de aula gera diversos debates sobre o modo como devem ser usadas e qual a sua influência no método ou na didática do professor, isto é, de que modo professores e alunos se apropriam de tais recursos como material didático, que métodos de leitura são empregados na análise dessa relaçáo. Como lembra Duarte (2004), a educação a ser oferecida exige novos pressupostos, entre eles aquele que admite a produção de textos em imagem-som e a consequente difusão de conhecimentos que possam ter legitimidade, confiabilidade e valor epistemológico, tais como outras fontes usadas em sala de aula. Nesse caminho, é visível como os recursos audiovisuais ocupam, hoje, "um lugar estratégico na dinâmica da cultura cotidiana das maiorias, na transformação das sensibilidades, nos modos de construir imaginários e identidades" (Martín-Barbero, 2001, p. 26).

Neste sentido, o presente artigo refletirá a respeito do uso dos recursos audiovisuais, mais especificamente o uso de documentários em sala de aula, e como eles contribuem para o professor de História e para o fazer histórico. O foco deste artigo recai sobre o documentário, que é uma forma de cinema ou de programa televisivo, visto que pode ser produzido tanto para o primeiro quanto exclusivamente para o segundo. Para debater o assunto, faz-se necessário o recorte sobre o uso do cinema, recurso audiovisual que possui uma maior bibliografia sobre como deve ser usado em sala de aula e onde se encontra o gênero classificado como documentário.

Como bem aponta Rossini (2006, p. 113-114), desde seu nascimento,

[...] em fins do século XIX, o cinema passou a atrair a atenção do grande público, tornando-se, ao longo do século $\mathrm{XX}$, uma imponente indústria produtora e difusora de sonhos, comportamentos, memórias, versôes de histórias. Ao cinema, em meados daquele século, veio juntar-se a televisão, que rapidamente se tornou o principal meio de comunicaçáo de milhares de pessoas ao redor do mundo.

Contudo, a aceitação e a utilização de recursos tecnológicos, mais especificamente os audiovisuais, como fonte para o historiador ou como recurso em sala de aula não foi um caminho fácil. Segundo Bittencourt 
(2004), desde 1912 existem registros de tentativas do uso de filmes com os alunos. Segundo ele, Jonathas Serrano, professor de História do Colégio Pedro II, procurava incentivar seus colegas a "recorrer ao uso de filmes de ficção ou documentários para facilitar o aprendizado da disciplina” (Bittencourt, 2004, p. 371). Mas esse é um caso isolado. Para a maioria dos educadores, a televisão e o cinema eram considerados um grande "empecilho ao aprendizado ou concorrente incômodo e difícil de ser vencido no processo de educação escolar" (Bittencourt, 2004, p. 372).

Possível motivo para o pouco uso dos recursos audiovisuais por professores de História, segundo Bittencourt (2004, p. 373):

O desprezo de muitos historiadores para com o cinema fez que este, conseqüentemente, náo fosse tópico tratado nos cursos de graduaçáo e de formação docente e favoreceu, nas aulas de História, uma prática de utilização desse recurso desvinculada de fundamentos metodológicos.

Entretanto, tal realidade está se alterando. Nas palavras de Almeida (apud Napolitano, 2008, p. 12), "embora o cinema já seja utilizado há algum tempo por muitos professores, pelo menos desde o final dos anos 1980, só mais recentemente surgiram algumas propostas mais sistematizadas que orientam o professor". A capacidade e as possibilidades que os recursos audiovisuais propiciam não podem ser negadas, uma vez que podem transformar a escola em ambiente vívido, participante ativo da cultura, atentando e atendendo a necessidades imediatas da sala de aula, dos alunos e do círculo social no qual estâo inclusos, e em um meio repetidor ou divulgador de conhecimentos massificados.

\section{As RELAÇÓES ENTRE FILMES E ENSINO}

A relação entre o ensino e o uso de novos meios de comunicação, como o cinema, é próxima, sendo que desde o início a produção audiovisual foi considerada como um poderoso instrumento de educação e instrução. Para refletir a respeito dessa questão, basta relembrar alguns casos que extrapolam a sala de aula, como os cinejornais, ou actualités, que eram exibidos antes dos filmes, exercendo um grande poder de convencimento sobre a população em geral. Como exemplo mais fértil para debate, há o momento da 2a Guerra Mundial quando os Estados Unidos lançam o fil- 


\section{Revista Solta a Voz, v. 20, n. 2}

me A estrela do Norte, de Lewis Milestone (1943), enaltecendo o povo soviético, com o fim de justificar aos norte-americanos a aliança com a União das Repúblicas Socialistas Soviéticas (URSS) contra a Alemanha nazista. O filme alcança seus propósitos e, com o fim da guerra, é proibido em território americano. Como exemplos mais atuais, é possível citar o documentário Uma verdade inconveniente (2006), dirigido por Davis Guggenheim e apresentado pelo ambientalista e ex-vice-presidente dos Estados Unidos Al Gore, que analisa questóes ambientais e como a humanidade "consome" o planeta Terra. É um filme de impacto e foi usado por diversos professores e ambientalistas para influenciar a população de um modo geral para fins de educação ambiental. A repercussão foi tamanha que recebeu o Oscar de melhor documentário. Mas se for observada a mensagem no fim do filme ("Pisamos na Lua! Ótimo exemplo do que é possivel quando nos empenhamos. Trabalhamos juntos para derrotar o comunismo..."), a questáo ideológica do chamado "estilo de vida americano" e do "dever americano" fica evidenciada.

Dizer que os meios audiovisuais não possuem poder ou influência sobre a cultura ou o social de uma pessoa é um posicionamento equivocado, assim como dizer que a sociedade e a cultura pouco influenciam a escolha de um tema na criação de um filme. Para Ernest Gombrich (2007), todo artista visual (neste caso, o cineasta) possui seu trabalho condicionado por padróes culturais de fundo inconsciente e que interferem em seu estilo artístico (padróes estéticos e sociais vigentes de forma consciente).

Contudo, como dito anteriormente, foram poucos os estudos a respeito da relaçáo entre o ensino e os meios audiovisuais, a maior parte deles, no caso do Brasil, realizados após 1980 e focando aspectos mais ilustrativos, tratando a questão de forma generalizada. Somente no início dos anos 1990, com a abertura para livros de autores estrangeiros, como Marc Ferro, é que o cinema adquiriu forma mais crítica, em que os pesquisadores buscaram contextualizar a produção no tempo em que foi feita. O livro de Ferro, Cinema e História, tem seu foco, como o próprio título fala, no cinema, mas sua leitura pode ser usada para todos os outros meios audiovisuais, assim como o trabalho de Nöel Carroll (2005) sobre leitura e compreensão de documentários pode ser utilizado para a interpretação de fontes literárias. Os autores utilizados possuem viés interdisciplinar, assim como o presente trabalho. 
A relação entre o ensino e o uso de filmes em sala de aula é profícua, sendo que a maioria dos trabalhos conclui que tais recursos aperfeiçoam a relaçâo ensino-aprendizagem. Segundo Carnes (1997, p. 20),

A hora do livro, ou melhor, o milênio do livro, observou Gore Vidal, já era. Se a palavra impressa superou a tradição oral, o cinema e a televisão eclipsaram a suprema invenção de Gutenberg. Vidal sugere que cedamos ao inevitável, que descartemos o sistema educacional vigente e que apresentemos o passado aos jovens através do cinema. A idéia não é tão radical assim, nem sequer tão profética. Muitos professores de História, tendo como alunos telespectadores inveterados, vêm dedicando bom tempo de aula a filmes como 1492, Gandhi e Malcolm X. As distribuidoras de vídeo têm nos colégios um mercado importante. E filmes antigos continuamente reprisados na televisão funcionam como uma escola noturna, um grande repositório de consciência histórica em nossos Estados Unidos da Amnésia. Para muita gente, a História hollywoodiana é a única história que existe.

Esse pode ser considerado um posicionamento mais radical, mas há de se considerar que o cinema, hoje, se torna fundamental como ferramenta a ser utilizada pelo professor de História em sala de aula. Porém, cabe ao historiador-professor a orientaçáo de como o seu aluno deve assistir a um filme ou uma obra de cunho cinematográfico, elevando o aluno da condiçấo antes exclusiva de receptor para uma dimensão que lhe proporcione visão diferenciada, olhar mais consciente, crítico e até autocrítico.

\section{O documentário e a sala de Aula}

Vários foram os estudos a respeito desse assunto, seja utilizando o audiovisual como fonte ou como meio para o ensino em sala, a maioria deles sempre com um foco no cinema, tendo visão ampla, deixando de lado uma análise mais específica de seus gêneros fílmicos, entre eles um que é usado por muitos professores para "ilustrar algo real", ou seja, a realidade: o documentário.

Para Cristiane Nova (1996),

Os documentários, não obstante a sua aparente objetividade, também são representaçôes sobre o passado e como tais devem ser tratados. A seleção do tema, dos fatos abordados, das imagens e o seu encadeamento, a música 


\section{Revista Solta a Voz, v. 20, n. 2}

utilizada, o conteúdo do texto narrado e a sua inserção, tudo isso faz parte do universo de subjetividade presente no filme, que deve ser abordado à luz da relação passado-presente.

Isso ocorre porque, para muitos educadores e estudiosos do assunto - historiadores, comunicadores sociais, cinéfilos, cineastas, documentaristas, etc. -, o documentário é classificado como tal a partir de conceitos como objetividade, verdade e realidade. Tais conceitos complicam a análise desse tipo de película. Para um bom uso do documentário, é fundamental conhecer o que forma o documentário.

Segundo Fernão Pessoa Ramos (2008), o que difere um filme de ficção de um documentário é que este faz asserçóes ou proposiçóes tangentes ao mundo histórico. Pode-se dizer que o documentário é uma forma de narrativa que utiliza o recurso fílmico e estilos diversos para passar sua mensagem. Assim, ao "estabelecer asserçóes relativas ao mundo, o documentário admite procedimentos que o singularizam com relação ao campo ficcional. O documentário, antes de tudo, é definido pela intenção do autor de fazer um documentário" (Ramos, 2008, p. 25).

Já Nöel Carroll (2005, p. 91) define documentário como um filme não-ficcional, uma película de asserção pressuposta, que seria um filme que "se e apenas envolve uma intenção de sentido por parte do cineasta que fornece a base para a compreensão de sentidos pelo público, assim como uma intenção assertiva por parte do cineasta que serve como base para a adoção de uma postura assertiva pelo público”.

Nessas e em outras definiçóes do que é documentário, é possível observar um intenso debate sobre ficção e não-ficção. Nos parágrafos anteriores, é clara a referência à ficção, pois, na busca por uma definição do que é documentário, define-se o que é ficção e não-ficção, para então aprofundar no que vem a ser um documentário de fato. Tal debate ocorre por diversos motivos, dentre eles o de que os documentários seriam verdades. Tal assertiva é perigosa, pois não há um real, uma verdade, mas verdades. Como é dito na história, há a pluralidade, pois o que nos chega, seja por meio literário ou fílmico são representaçóes, que "não são idênticas àquilo que representam" (Carroll, 2005, p. 75), são veículos representacionais.

Essa forma de "ler" o documentário se aproxima muito do fazer do historiador. Nesse campo, são importantes as reflexóes de Keith Jenkins (2005), ao assinalar que embora a história, isto é, a produção histórica, seja 
um discurso sobre o passado, está em uma categoria diferente dele. Tal diferenciação se evidencia quando atentamos para o fato de que o passado já aconteceu e não pode mais ser recuperado, muito menos fidedignamente, como supôs o projeto positivista. Recupera-se não o passado, mas visóes a respeito dele, sendo que tais visóes dependem da lente que o historiador usou. Assim, o enfoque que o historiador utiliza em sua análise - político, econômico, social ou cultural - estabelece a importância, o significado por ele conferido à dimensão do relato do passado que ele priorizou no acento predominante. Uma forma de conceber a escrita da história semelhante à visão de Paul Veyne, segundo a qual como tudo é história, a história termina sendo o que foi escolhido pelo historiador. Ou como concebe Jenkins (2005, p. 28-29), ao afirmar que "nenhum relato consegue recuperar o passado tal qual ele era, porque o passado são acontecimentos, situaçóes etc., e não um relato. Já que o passado passou, relatos só poderão ser confrontados com outros relatos, nunca com o passado".

[...] o mundo ou o passado sempre nos chegam como narrativas e não podemos sair dessas narrativas para verificar se correspondem ao mundo ou ao passado reais, pois elas constituem a 'realidade' [...] Sociólogos e historiadores diferentes interpretam de maneira distinta o mesmo fenômeno, por meio de outros discursos que estão sempre mudando, sempre sendo decompostos e recompostos, sempre posicionados e sempre posicionandose, e que por isso precisam que aqueles que os usam façam uma autocrítica constante [...] não importando o quanto a história seja autenticada, amplamente aceita ou verificável, ela está fadada a ser um constructo pessoal, uma manifestação da perspectiva do historiador como 'narrador' [...] vemos por intermédio de um intérprete que se interpóe entre os acontecimentos passados e a leitura que deles fazemos [...] O passado que 'conhecemos' é sempre condicionado por nossas próprias visôes, nosso próprio 'presente'. Assim como somos produtos do passado, assim também o passado conhecido (a história) é um artefato nosso. (Jenkins, 2005, p. 32-33)

Nesta perspectiva, entende-se que o trabalho por excelência do historiador é o de narrador, pois seu discurso, "qualquer que seja sua forma, é sempre uma narrativa” (Chartier, 1994, p. 3). Pode-se dizer, então, que o trabalho do documentarista também é o de um narrador. Como bem lembra Vladimir Carvalho, "o trabalho de um documentarista é muito mais o de extrair textos do contexto [...] e montar outro texto, dessa vez fílmico, 


\section{Revista Solta a Voz, v. 20, n. 2}

costurando os fragmentos de 'mundo real' que foi possível registrar imageticamente" (apud Duarte, 2009).

Por serem formas de narrativa, tanto a história quanto o documentário podem utilizar recursos ficcionais para transmitir seu conteúdo, e não deixarão de ser documentário ou história, "pois qualquer estrutura lingüística, estilo de texto ou atributo textual característico da ficção são passíveis de apropriação pelo autor não-ficcional com vistas a uma diversidade de efeitos estéticos" (Carroll, 2005, p. 76).

Ramos (2008, p. 31-32) traz que "na medida em que se propóe a estabelecer asserçóes sobre o mundo histórico, o documentarista estará lidando diretamente com reconstituição e a interpretaçáo de um fato que, no passado, teve a intensidade do presente" [grifos do autor]. Temos outro ponto em que a história e o documentário se cruzam, o de que são interpretaçóes sobre fatos, não existindo verdade fechada, mas asserçóes sobre o que ocorreu.

Tais asserçôes serão legíveis e perceptíveis por meio do discurso narrativo em que apresentará o resultado de seu trabalho.

Mostrou-se que toda interpretação histórica depende de um sistema de referência; que este sistema permanece uma 'filosofia' implícita particular; que infiltrando-se no trabalho de análise, organizando-o à sua revelia, remete à 'subjetividade' do autor [...] Os 'fatos históricos' já são constituídos pela introdução de um sentido na 'objetividade'. Eles enunciam, na linguagem da análise, escolhas que lhes são anteriores, que não resultam, pois, da observaçáo [...] sobre o fundo de uma totalidade histórica, se destaca uma multiplicidade de filosofias individuais, as dos pensadores que se vestem de historiadores. (Certeau, 2007, p. 66)

Jurandir Malerba (2006) percorre um caminho parecido com o de Jenkins e Certeau, seguindo por uma vertente narrativista, propondo que a história produzida pelos historiadores é uma forma de narração, mas se diferencia de outras formas do gênero de narração por possuir método para sua escrita. Para ele, não é permitido ao historiador devanear sobre um determinado assunto, visto que deve seguir regras metodológicas para a formulação e apresentação dos resultados de sua pesquisa. Além de tal característica, deve-se ter em consideração a própria historicidade que precede o conhecimento histórico, tributário das contribuiçóes que a antecedem, direta ou indiretamente. 
Todavia, ao público não especializado não importa o quão teórico se propõe um trabalho, seja literário ou fílmico, mas sim o seu conteúdo e, sobretudo, a forma como foi explicitado. Segundo Ranke (1835 apud Rüsen, 2007, p. 18),

A história distingue-se das demais ciências por ser, simultaneamente, arte. Ela é ciência ao coletar, achar, investigar. Ela é arte ao dar forma ao colhido, ao conhecido e ao representá-los. Outras ciências satisfazemse em mostrar o achado meramente como achado. Na história, opera a faculdade da reconstituição. Como ciência, ela é aparentada à filosofia; como arte, à poesia.

Tais colocaçóes se aproximam muito do fazer do documentarista, pois, segundo Ramos (2008, p. 25), “o documentário caracteriza-se pela presença de procedimentos que o singularizam com relação ao campo ficcional. O documentário, antes de tudo, é definido pela intenção de seu autor de fazer um documentário" [grifo do autor]. O mesmo ocorre com a história, pois, para que seja aceita a narrativa como histórica, há a exigência da exposição do método utilizado. Como observado por Certeau, métodos possuem a função de iniciação de um grupo, ou seja, para que se possa escrever sobre história e ser aceito entre pares, é necessário seguir regras, ou seja, métodos. Da mesma forma que os métodos têm função social de proteger, diferenciar e manifestar o poder de um corpo de mestres e de letrados (Certeau, 2007, p. 73), também possuem a função de indexar e rotular. Indexação que ocorre "através de mecanismos sociais diversos, direcionando a recepção” (Ramos, 2008, p. 27).

Não difere do documentário, que, mesmo a maioria deles não tendo viés científico ou acadêmico, possui uma forma de ser feito, uma intenção que o caracteriza como documentário. "Um documentário pode certamente mostrar algo que não é real e continuar a ser documentário" (Ramos, 2008, p. 30), pois o que o define como documentário está sustentado em duas pernas: estilo e intenção, que estão em estreita interação ao serem lançadas para a fruição espectatorial, que as percebe como próprias de tipo narrativo que possui determinaçóes particulares.

A partir do exposto, tem-se a dúvida se, por exemplo, a ficção histórica não seria uma forma de documentário. Novamente é Ramos que apresenta uma forma de distinção. De acordo com ele, o que difere é que 


\section{Revista Solta a Voz, v. 20, n. 2}

a ficção utiliza estruturas narrativas marcadas pelo "classicismo hollywoodiano", não enunciando como fazem os documentários. A ficção é feita para ser fruída pelo espectador, ou seja, levá-lo a se entreter. A expectativa do espectador sobre os personagens, a verossimilhança com a história "são elementos que constituem a fruição da ficção” (Ramos, 2008, p. 52). A história, em si, não basta para a ficção histórica. Ela vai necessitar de uma trama, com personagens que relatem o fato ocorrido. Como exemplo podese lembrar do filme Titanic, de James Cameron, do qual todos sabiam o fim - naufrágio do navio - mas para contar essa história se criou um enredo com personagens e conflitos, em que o público "torcia" pela heroína e pelo herói. A ficção histórica "toma a realidade histórica enquanto matéria básica e a retorce para que caiba dentro da estrutura narrativa, conforme delineada pelo classicismo hollywoodiano" (Ramos, 2008, p. 53), [grifo do autor].

Já no documentário, o espectador não espera um filme para entretenimento, muitas vezes um faz de conta. Na maior parte das vezes, o espectador não frui, pois espera ver uma apresentação da "verdade". E é dessa forma, esperando que se apresente a verdade sobre um fato, que a maior parte dos professores apresenta esse gênero em sala de aula. Contudo, afirmar que um documentário, assim como um livro de história, aponte a verdade é perigoso. Pelo mesmo caminho, a história não é mera literatura, ficção, pois quando o leitor vai a uma obra histórica busca a "verdade", ou seja, frui como a um documentário.

Tendo esta dimensão em vista, a de que o espectador lê um documentário como uma apresentação da "verdade", o documentário assume um papel, como recurso audiovisual muito importante, para além do que o cinema de ficção pode alcançar. Seu uso em sala de aula é de grande importância, pois, como bem posiciona Duarte (2009), "a escola desempenha importante papel no processo de legitimação de produtos culturais". Neste sentido, o documentário, diferentemente do filme ficção, abre um leque de possibilidades, pois se o professor o utilizar, mesmo que como ilustração (o que é refutado neste artigo), "ajuda a desconstruir a idéia, relativamente comum, de que eles são um retrato fiel da realidade ou que os acontecimentos de que eles se ocupam se passaram exatamente como são relatados" (Duarte, 2009).

Para trabalhar o documentário com os alunos, propóe-se que ele não seja utilizado para ilustrar, mas para apresentar o fazer histórico, como a história é feita e suas diversas formas de escrita, comparando-o ao fazer 
documentário. Isso colocado, há de se lembrar que qualquer profissional da educação que queira utilizar algum recurso audiovisual em sala de aula deve ter um mínimo de conhecimento técnico sobre o assunto. Negar tal saber é cair na armadilha de um cine-ilustração. Os recursos audiovisuais (dentre eles, o documentário) devem gerar um novo conhecimento, e não simplesmente interpretaçóes superficiais.

Como bem lembra Ulpiano Meneses, a utilização de recursos audiovisuais vem de encontro ao papel fundamental da história, ou seja, o de estudar a sociedade - toda a sociedade. "Não se estudam fontes para melhor conhecê-las, identificá-las, analisá-las, interpretá-las e compreendêlas, mas elas são identificadas, analisadas, interpretadas e compreendidas para que, daí, se consiga um entendimento maior da sociedade" (Meneses, 2003, p. 26).

Neste sentido, entendendo as relaçóes possíveis entre o fazer da história e do documentário e o objeto de estudos da primeira (ou seja, a sociedade), falar sobre como usar o documentário em sala de aula começa a ficar mais fácil, pois pode-se dizer que esse gênero fílmico acaba por adquirir a função de um enunciado, carregado de subjetividades e escolhas. Como enunciado, passa a ser não somente um testemunho histórico, mas a própria história. O professor deve mediar a relação da película com o aluno, integrando o filme "ao mundo social, ao contexto em que surge" (Cardoso; Mauad, 1997, p. 413).

Napolitano (2008, p. 31) ensina que

[...] o professor deve evitar partir do principio que a abordagem dada ao documentário é a única possível ao tema retratado ou que o conteúdo mostrado é a realidade social ou a verdade científica sobre o assunto. $\mathrm{O}$ documentário [...] é um gênero de filme que implica um conjunto [...] de escolhas dos profissionais envolvidos na sua realização.

Portanto, para trabalhar o documentário em sala de aula é ideal que o professor aponte interpretaçóes e apresente um debate, nunca para a desqualificação da obra, mas sim para problematizá-la.

Como exemplo para esse tipo de empreitada podem ser usados dois filmes que tratam do mesmo assunto com visões diferentes, mas que não deixam de ser documentários. O primeiro é $A$ revolução não será televisionada, feito por um grupo de irlandeses e que mostra o que ocorreu na 
Venezuela durante o ano de 2001, quando houve uma tentativa de golpe contra o presidente Hugo Chávez. O documentário recebeu diversos prêmios no mundo inteiro. Mostrado em salas de aula e circuitos alternativos, o vídeo mostra Chávez como vítima indefesa de uma mídia virulenta e de uma elite manipuladora e perversa. Vemos também como o povo supostamente saiu em defesa de seu grande líder e foi violentamente contido pelas tropas golpistas.

Já o segundo - Raio-X de uma mentira - , que é pouco conhecido no Brasil, funciona como uma espécie de making of de $A$ revolução não será televisionada. Realizado em uma universidade de Caracas durante um debate sobre $A$ revolução não será televisionada, vai questionar as manipulaçôes de imagem, a utilização de imagens antigas, a inversão cronológica, a colagem, a edição paralela e as omissōes, gravíssimas, no documentário dos cineastas irlandeses.

Com esses dois documentários apresentados aos alunos, é possível demonstrar o fazer histórico, demonstrando como um relato ou uma narrativa pode ser confrontado por outro que utilize as mesmas fontes, mas com métodos diferentes. Como exemplos podem ser citados livros como Raizes do Brasil, de Sérgio Buarque de Holanda; Casa Grande e Senzala, de Gilberto Freire, e a Formação do Brasil Contemporâneo, de Caio Prado Junior. Esses livros tratam da formação do Brasil, mas todos com perspectivas diferentes.

Outra forma de trabalhar o documentário seria por meio das representaçóes, pois, como o filme é uma visão do diretor/autor, do autor ou do produtor, carrega pré-conceitos sobre alguns moldes. Não se imagina uma película sobre o MST, produzida por uma pessoa alinhada ao movimento, que traga imagens dos integrantes do movimento como "vilóes". O mesmo pode ser aplicado a filmes como $A$ carne é fraca, que busca apresentar como é realizado o abate de animais que vão para a mesa do brasileiro, enaltecendo a importância de ser ou se tornar vegetariano. Todos são feitos com subjetividades e com a intenção de convencimento, ou seja, todos são feitos a partir de um lugar de fala social.

Assim como bem lembra Michel de Certeau, é importante saber o lugar social do autor da narrativa, seja ela histórica ou documentária. Como já dito, ao analisar o passado não se recupera o passado em sua totalidade, mas visóes sobre ele, sendo que estas variam conforme a lente teórica utilizada pelo historiador. Pode-se dizer que lugar social é onde se articulam a 
produção - historiográfica, cinematográfica, documentária - e o local de produção, os cânones - socioeconômico, político e cultural - que direcionam o pesquisador na hora da produção. Entender e analisar essa produção é "admitir que ela faz parte da 'realidade' da qual trata, e que essa realidade pode ser apropriada 'enquanto atividade humana”' (Certeau, 2007, p. 66).

\section{Conclusão}

Problematizar a produção documentária é uma forma de apresentar o conteúdo da disciplina escolar História, demonstrando ao aluno que essa disciplina não é simples "decoreba”, e sim uma visão da sociedade, uma problematização contínua, para que o aluno possa desenvolver sua capacidade de criticidade.

Alguns podem considerar esse modo de trabalhar pouco prático para o uso do documentário em sala de aula; contudo, a proposta é apresentar ao aluno uma forma de "ler" a história e entendê-la, compreendendo que a "realidade" não é dicotômica, não é branco e preto, mas que contém tons de cinza. Compreender esses tons de cinza é o que vai proporcionar ao aluno o desenvolvimento de sua capacidade de criticidade, tão almejada pelas leis brasileiras. Não basta criticar por criticar, e sim dar ferramentas e meios para que o aluno tenha uma crítica consistente, observando sua realidade e o que a cerca. Entender o lugar de fala de quem produz, seja a história, seja um filme ou o livro didático. Proporcionar tais meios é, afinal, o papel do professor em sala de aula.

\section{REFERÊNCIAS}

BITTENCOURT, Circe. Ensino de história: fundamentos e métodos. São Paulo: Cortez, 2004.

CARDOSO, Ciro Flamarion; MAUAD, Ana Maria. História e imagem: os exemplos da fotografia e do cinema. In: CARDOSO, Ciro Flamarion; VAINFAS, Ronaldo (orgs). Dominios da História: ensaios de teoria e metodologia. Rio de Janeiro: Elsevier, 1997.

CARNES, Mark. (Org.). Passado imperfeito: a história no cinema. Rio de Janeiro: Record, 1997. 


\section{Revista Solta a Voz, v. 20, n. 2}

CARROLL, Noël. Ficção, não-ficção e o cinema da asserção pressuposta: uma análise conceitual. In: RAMOS, Fernão Pessoa (org). Teoria contemporânea do cinema: documentário e narrativa ficcional. Volume II. São Paulo: Editora Senac, 2005.

CERTEAU, Michel de. A Escrita da história. 2 ed. Rio de Janeiro: Forense Universitária, 2007.

CHARTIER, Roger. A história hoje: dúvidas, desafios, propostas. Estudos Históricos: Rio de Janeiro, vol. 7, n. 13, p. 97-113, 1994.

. Crise na história? In: PESAVENTO, Sandra (org.). Fronteiras do milênio. Porto Alegre: UFRS, 2000.

DUARTE, Rosália. Cinema \& educação. Belo Horizonte: Autêntica, 2002.

. Documentários na escola. Disponível em: <www.grupem.pro.br/ docs/artigo5.pdf> Acesso em: jun. 2009.

DUARTE, Rosália; LEITE, Camila; MIGLIORA, Rita. Crianças e televisão: o que elas pensam sobre o que aprendem com a tevê. Revista Brasileira de Educação, v. 11, n. 33, set./dez. 2006.

FERRO, Marc. Cinema e história. Rio de Janeiro: Paz e Terra, 1992.

FREIRE, Marcius. Relação, encontro e reciprocidade: algumas reflexóes sobre ética no cinema contemporâneo. Revista Galáxia. São Paulo, n.14, p. 13-28, dez. 2007.

GOMBRICH, Ernest. Arte e Ilusão: um estudo da psicologia da representação pictórica. São Paulo: Companhia das Letras, 2007.

JENKINS, Keith. A História repensada. São Paulo: Contexto, 2005.

MALERBA, Jurandir (org.). A História escrita: teoria e história da historiografia. São Paulo: Contexto, 2006.

MARTÍN-BARBERO, Jesús; REY, German. Os exercícios do ver. São Paulo: Editora Senac, 2001.

MENESES, Ulpiano T. Bezerra. Fontes visuais, cultura visual, História visual: balanço provisório, propostas cautelares. Revista Brasileira de História. São Paulo, v. 23, no 45, p. 11-36, 2003. 
NAPOLITANO, Marcos. Como usar o cinema na sala de aula. São Paulo: Contexto, 2008.

NOVA, Cristiane. O cinema e o conhecimento da História. In: O Olho da História. Salvador, no 3, 1996. Disponível em: <http://www.oolhodahistoria. ufba.br/o3cris.html>. Acesso em: 16 maio 2009.

RAMOS, Fernão Pessoa (org). Teoria contemporânea do cinema: documentário e narratividade ficcional. Volume II. São Paulo: Editora Senac, 2005. . Mas afinal... o que é mesmo documentário? São Paulo: Editora Senac, 2008.

RANKE, L. von. Die idee der universalhistorie (1835). In: RÜSEN, Jörn. História Viva: teoria da história: formas e funçôes do conhecimento histórico. Brasília: Editora Universidade de Brasília, 2007.

RÜSEN, Jörn. Razão histórica: teoria da história: fundamentos da ciência histórica. Tradução de Estevão Rezende Martins. Brasília: EdUnB, 2001.

ROSSINI, Miriam de Souza. O lugar visual no fazer histórico: uma discussão sobre outras possibilidades do fazer histórico. In: PESAVENTO, Sandra Jatahy; LOPES, Antonio Herculano; VELLOSO, Monica Pimenta (orgs). História e linguagens: texto, imagem, oralidade e representaçôes. Rio de Janeiro: 7 Letras, 2006.

Recebido em: 04 jul. 2009

Aceito em: 30 set. 2009 